\title{
Discurso da promoção da igualdade de gênero da campanha HeForShe no Brasil e no México
}

Discourse of gender equality promotion in the HeForShe campaign in Brazil and in Mexico

\section{Discurso sobre la promoción de la igualdad de género en la campaña HeForShe en Brasil y México}

\section{Denise Avancini Alves}

- Doutora em Comunicação e Informação pelo Programa de Pós-Graduação em Comunicação e Informação da Universidade Federal do Rio Grande do Sul (UFRGS).

- Mestre em Administração pela UFRGS.

- Professora adjunta do curso de Relações Públicas da Faculdade de Biblioteconomia e Comunicação daUFRGS.

- E-mail: deniseavancinialves@yahoo.com.br

- Doutora em Ciências da Comunicação pela Universidade do Vale do Rio dos Sinos (Unisinos).

- Mestre em Comunicação pela Universidade Federal do Rio de Janeiro (UFRJ).

- Professora adjunta do curso de Publicidade e Propaganda e do Programa de Pós-Graduação em Comunicação da Escola de Comunicação, Artes e Design da Pontifícia Universidade Católica do Rio Grande do Sul (PUCRS).

- E-mail: cristiane.carvalho@pucrs.br

- Mestranda do Programa de Pós-Graduação de Direitos Humanos da Universidade Federal de Pernambuco (UFPE).

- Mestranda do Programa Educacional de Sociologia da Universidade Corvinus de Budapeste (Hungria) pela bolsa Stipendium Hungaricum.

- Graduada em Relações Públicas pela UFRGS.

- E-mail: carolinakauer@hotmail.com 


\section{Resumo}

O estudo foca na análise do discurso da promoção da igualdade de gênero a partir da campanha HeForShe no Brasil e no México, seus desdobramentos, apropriações e adequações frente ao contexto da pandemia da covid-19. Tem suporte na pesquisa bibliográfica e conteúdo da ONU Mulheres, acionando a Análise Crítica do Discurso de Fairclough ao realizar uma análise tridimensional do texto e das práticas discursiva e social. Resultados indicam similaridade na busca da corresponsabilidade dos homens na equidade de gêneros.

\section{PALAVRAS-CHAVE: DISCURSO • IGUALDADE DE GÊNERO • CAMPANHA HEFORSHE • CAMPANHA ELESPORELAS•AMÉRICA LATINA.}

\section{Abstract}

The study analyzes the discourse of gender equality promotion in the HeForShe campaign in Brazil and Mexico, as well as its consequences, appropriations, and adaptations in the context of the COVID-19 pandemic. To this end, a bibliographic and content research of the UN-Women's websites was performed and submitted to Critical Discourse Analysis (FAIRCLOUGH, 2001) through a three-dimensional analysis of the text, discursive practice, and social practice. Results indicate the similarity in the pursuit of men's co-responsibility in gender equality.

\section{KEYWORDS: DISCOURSE • GENDER EQUALITY • CAMPAIGN HEFORSHE • CAMPAIGN ELESPORELAS • LATIN AMERICA.}

\section{Resumen}

Este estudio se centra en el análisis del discurso sobre la promoción de la igualdad de género de la campaña ÉlPorElla en Brasil y México, así como sus consecuencias y adaptaciones en el contexto de la pandemia del covid-19. Se apoya en la investigación bibliográfica y de contenido de los sitios web de ONU Mujeres, utilizando el análisis crítico del discurso de Fairclough mediante la realización del análisis tridimensional del texto, la práctica discursiva y la práctica social. Los resultados indican la similitud en la búsqueda de la corresponsabilidad de los hombres en la igualdad de género. 


\section{INTRODUÇÃO}

Prevista na Declaração Universal dos Direitos Humanos (DUDH), de 1948, a igualdade de gênero ganhou importância também nas Organizações das Nações Unidas (ONU), configurando-se como quinto Objetivo de Desenvolvimento Sustentável (ODS) para 2030. De forma específica e resgate histórico, para dar luz e maior ênfase ao tema, desde 2010 existe a Entidade das Nações Unidas para a Igualdade de Gênero e o Empoderamento das Mulheres, conhecida como ONU Mulheres, que foi criada "para unir, fortalecer e ampliar os esforços mundiais em defesa dos direitos humanos das mulheres", conforme o site da organização'. Sua apresentação institucional reforça ainda o "apoio a articulações e movimento de mulheres e feministas, entre elas mulheres negras, indígenas, jovens, trabalhadoras domésticas e trabalhadoras rurais".

Conforme explicita em sua página, a entidade apresenta seis áreas prioritárias de atuação: liderança e participação política das mulheres; empoderamento econômico; fim da violência contra mulheres e meninas; paz e segurança e emergências humanitárias; governança e planejamento; normas globais e regionais.

Um dos movimentos da organização se consolida na campanha ${ }^{2}$ HeForShe (ElesPorElas), considerada uma das primeiras e mais conhecidas campanhas globais da ONU Mulheres, criada em setembro de 2014 como "um esforço global para envolver homens e meninos na remoção das barreiras sociais e culturais que impedem as mulheres de atingir seu potencial, e ajudar homens e mulheres a modelarem juntos uma nova sociedade"3.

Além do site global - que não possui adaptações regionais além do caráter de tradução -, percebe-se o site da ONU Mulheres como principal fonte oficial das informações acerca da campanha, sendo os sites regionais focados em ações localizadas, com desdobramentos de narrativas mais aderentes à cultura regionalizada e ao enfrentamento dos problemas mais evidentes em cada país. No caso da América Latina, além do site do escritório regional, estão disponíveis os dos escritórios nacionais do Brasil, Colômbia, Equador e México, além de uma oficina multinacional no Caribe.

Em estudos anteriormente realizados pelas autoras (Kauer; Alves; Carvalho, 2020), percebe-se o destaque do envolvimento de dois países: Brasil e México. No primeiro, há uma adesão à campanha através de versionamento linguístico e adaptação com o uso da hashtag \#ElesPorElas, além de promover a visibilidade da campanha por intermédio de celebridades brasileiras. O México, por sua vez, é um país que se destaca na apropriação do movimento \#HeForShe, principalmente com o enfoque da projeção da mulher na política do país, ampliando seu espaço de presença e representação.

Diante da oportunidade de analisar o discurso de uma campanha de mobilização social de caráter global, o tema se cristaliza, tendo como escopo principal a promoção da igualdade de gênero. Assim, o presente estudo tem como objetivo analisar 0 discurso e a apropriação da campanha HeForShe nesses dois países, Brasil e México, observando as adaptações discursivas realizadas frente ao contexto atual, considerando a pandemia global e o impacto desse cenário na promoção da igualdade.

Para atingir seu objetivo, o presente estudo se sedimenta com o suporte de pesquisa bibliográfica e acesso aos conteúdos dos sites da ONU Mulheres dos países selecionados. Para o exame dos dados, aciona a Análise Crítica do Discurso (ACD), conforme Fairclough (2001), utilizando uma análise tridimensional do texto, prática discursiva e prática social.

\footnotetext{
1 Disponível em: http://www.onumulheres.org.br/onu-mulheres/sobre-a-onu-mulheres/. Acesso em: 21 abr. 2021.

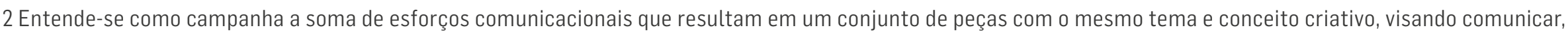
anunciar e informar, conforme suporte teórico de Sampaio (2003).

3 Disponível em: http://www.onumulheres.org.br/elesporelas/. Acesso em: 21 abr. 2021.
} 


\section{REFERENCIAL TEÓRICO}

A mobilização social é determinante no processo de emancipação e mudança social, que se estabelece "[...] quando um grupo de pessoas, uma comunidade ou uma sociedade decide e age com um objetivo comum, buscando, quotidianamente, resultados decididos e desejados por todos" (Toro; Werneck, 2004, p.13). Os sujeitos, quando dotados de um sentido de liberdade e de autonomia na configuração de suas redes relacionais e de interações, se aproximam do que os autores indicam como um processo de convocação de vontades para uma mudança de realidade, mediante propósitos comuns, estabelecidos em consenso. Tal convocação "envolve o compartilhamento de discursos, visões e informações e, por isso, exige ações de comunicação em seu sentido mais amplo" (Mafra, 2010, p.11).

Gerar este sentimento - ou seja, mobilizar-é, portanto, "[...] convocar vontades para atuar na busca de um propósito comum, sob uma interpretação e um sentido também compartilhados" (Toro; Werneck, 2004, p.13) e demanda a partilha de um objetivo em comum, cunhado como um horizonte ético que concede sentido. Em estudo anterior (Kauer; Alves; Carvalho, 2020), destaca-se a igualdade de gênero como um tema que atua, de forma crescente, como horizonte ético presente em projetos de mobilização na última década. Embasado na luta contra o tratamento mundialmente generalizado desigual e inferior de indivíduos do gênero feminino, 0 ativismo das mulheres - dividido historicamente nas três ondas do feminismo conquistou e trabalha para conquistar, em diversos países, os direitos humanos das mulheres, desde o voto feminino até a proteção contra a violência de gênero.

Voltando o olhar para a América Latina, há consenso entre os pesquisadores sobre o tema da igualdade de gênero e sua importância para o desenvolvimento sustentável dos países. Ainda assim, a região continua sendo uma das mais desiguais e, recentemente, passou a enfrentar perigos de retrocessos em decorrência de um conservadorismo político e social emergente (Cepal, 2019).

Como expõe Marta Lamas (2007), a América Latina apresenta perspectivas alentadoras, mas deprimentes. Apesar dos avanços claros, também são evidentes as desigualdades persistentes e as ameaças de retrocesso, que, em alguns casos, já ocorrem. Lamas também destaca como "as assimetrias que historicamente têm regido a relação entre homens e mulheres se agravam em contextos multiétnicos, multiculturais e multilíngues" (2007, p.134, tradução nossa), e isso se torna claro ao olhar não só para as desigualdades de renda entre os gêneros, mas também ao observar que mulheres negras e indígenas recebem significantemente menos que seus pares masculinos e ainda menos que mulheres brancas, com uma desigualdade que aumenta quanto maior o nível de educação (Cepal, 2019; Lamas, 2007).

A autora ainda destaca um problema característico da América Latina e intrinsecamente conectado às opressões sofridas pela mulher latina: a maternidade forçada. Para ela, não só há a necessidade de uma maior educação sexual e de informações sobre contraconceptivo para jovens mulheres, mas também da legalização do aborto, fato que, no mínimo, evidencia um problema de justiça social, já que "[...] as mulheres com recursos abortam sem perigo nos consultórios particulares de seus ginecologistas, enquanto as demais arriscam sua saúde e vida" (Lamas, 2007, p.138, tradução nossa). A resistência à descriminalização do aborto, no entanto, não demonstra enfraquecimento em diversos países, pois está profundamente ligada à influência religiosa sobre os políticos e legisladores e com a baixa incidência feminina na política. Mesmo no caso recente da Argentina, ainda é necessário mudar diversas normas sociais, arranjos institucionais e relações de poder para que se possa diminuir a brecha de execução, ou seja, a lacuna entre os direitos sancionados e sua efetiva realização (Riggirozzi; Grugel, 2021). 
Lamas esclarece umas das perspectivas da relação entre a maternidade forçada e a persistente divisão sexual do trabalho: "o círculo vicioso da maternidade precoce, número de filhos, falta de educação e menos capacitação profissional constituem uma 'estrutura de desvantagem' que reforça a pobreza, a desigualdade e a marginalização" (Lamas, 2007, p.135). A isso se soma o trabalho doméstico não remunerado e o trabalho de cuidado humano, ambos ainda considerados destino "natural" das mulheres da região. Esta situação foi intensificada na pandemia da covid-19 e certamente causa e causará maiores dificuldades para as mulheres latino-americanas.

Para pensar melhor nas questões interseccionais que assolam mulheres em contextos multiétnicos - tais como os encontrados na área geográfica focalizada no presente artigo -, faz-se necessário estudar como as estruturas que contribuem para as violações dos direitos humanos se relacionam. Kimberlé Crenshaw (2002) ressalta o avanço do debate de gênero em relação ao de raça e fala sobre alguns dos dilemas na incorporação da perspectiva interseccional à luta pelos direitos humanos. $A$ autora traz a noção de "'diferenças que fazem diferença' na forma como vários grupos de mulheres vivenciam a discriminação" (Crenshaw, 2002, p.173). É possível afirmar que há uma certa invisibilização dessa interseccionalidade que precisa ganhar luz e se fazer presente no combate à desigualdade de gênero, já que seu caráter estrutural, como aponta Crenshaw, faz que políticas ou decisões gerem fardos desproporcionais para certos tipos de pessoa, mesmo que não intencionalmente.

Com base nesse percurso reflexivo, pode-se destacar o papel da ONU Mulheres na promoção da igualdade através de seu discurso e pelo desdobramento de suas campanhas e ações, o que responde, de certa forma, ao olhar de Boaventura de Souza Santos (2001, p.35), "[...] não há identidade sem diferença e a diferença pressupõe uma certa homogeneidade que permite identificar o que é diferente nas diferenças". Identidade pressupõe diferença, mas, aqui, busca-se localizar os direitos humanos nessa diferença.

\section{METODOLOGIA}

A Análise Crítica do Discurso (Fairclough, 2001) oferece suporte para o presente percurso metodológico, uma vez que estuda as interações sociais a partir da análise de textos, com ênfase na mudança social a partir da mudança discursiva, no ponto em que uma implica a outra mutuamente, conforme pode ser observado em sua leitura tridimensional, presente na Figura 1.

Figura 1: Concepção tridimensional do discurso

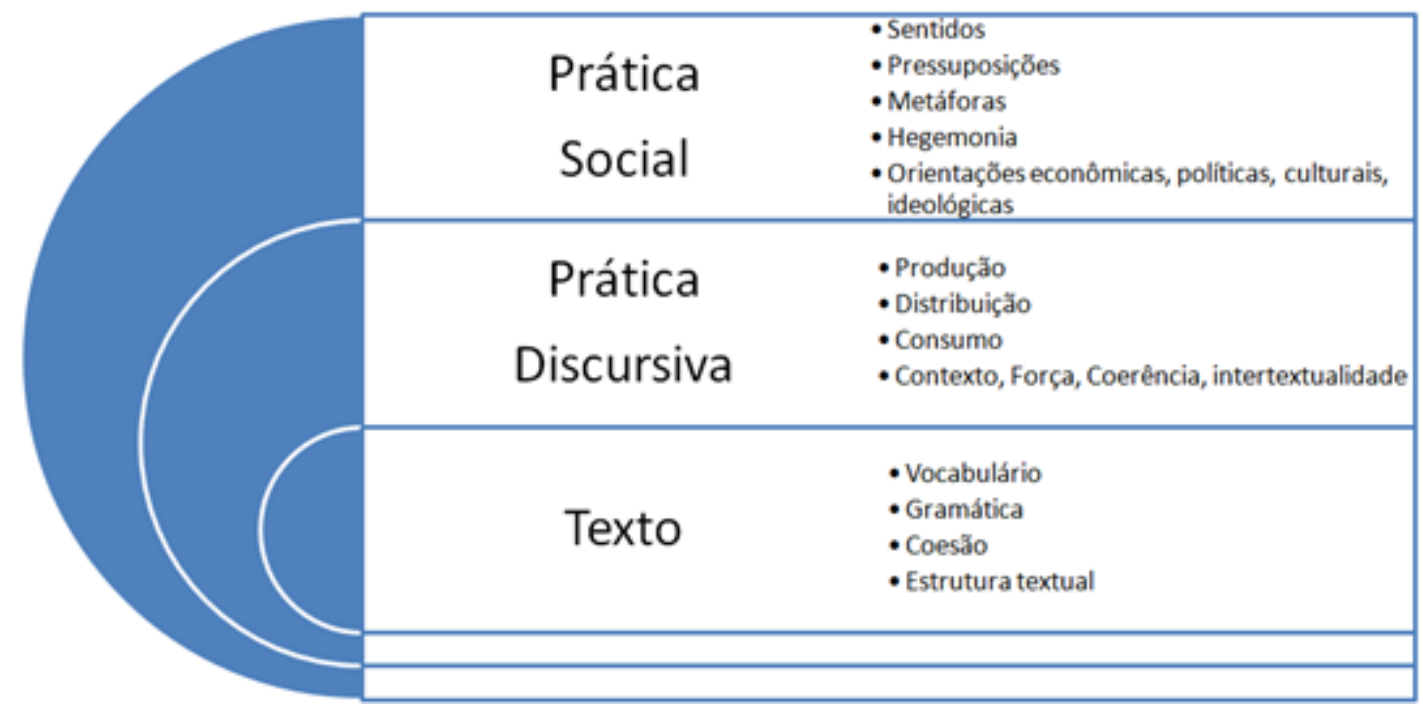

Fonte: adaptado de Fairclough (2001).

Assim, a proposta de Fairclough (2001) considera uma análise de discurso 
[...] que focalize a variabilidade, a mudança e a luta: variabilidade entre as práticas e heterogeneidade entre elas como reflexo sincrônico de processos de mudança histórica que são moldados pela luta entre as forças sociais (Fairclough, 2001, p.58-59).

Fairclough (2001, p.58) afirma que a "análise de discurso preocupa-se não apenas com as relações de poder no discurso [...] mas também com a maneira como as relações de poder e a luta de poder moldam e transformam as práticas discursivas de uma sociedade ou instituição". Assim, a ACD auxilia na análise do discurso da campanha HeForShe - promovida pela ONU Mulheres - nos países selecionados, partindo do texto de suporte, mas ampliando seu olhar para além dele, observando 0 contexto discursivo e promovendo reflexões sobre a realidade ou mudança social produzida. Fairclough (2001, p.90) propõe usar o termo discurso para designar "o uso de linguagem como forma de prática social", ou seja, tomá-lo como uma forma de ação, o que se percebe de forma evidente na campanha da ONU Mulheres. 0 autor sublinha que "o discurso é uma prática não apenas de representação do mundo, mas de significação do mundo, constituindo e construindo o mundo em significado" (p.91).

Orientada por essa abordagem, a metodologia base deste estudo considera duas etapas de análise, com vistas a dar conta dos objetivos propostos: 1) identificar como a campanha e seus resultados são apresentados no site da ONU Mulheres nos dois países; 2) relacionar os achados com os contextos locais e contingência global, como a pandemia.

\section{RESULTADOS}

A campanha HeForShe (ElesPorElas) foi lançada em 20 de setembro de 2014 como um dos movimentos da ONU Mulheres. Um dos motes da campanha é a abordagem de inclusão dos homens no debate, buscando seu engajamento para novas relações de gênero. Nos países da América Latina, o lançamento aconteceu no ano seguinte, 2015, com desdobramentos e adaptações feitas conforme a lacuna mais latente em cada país e seus contextos sociais, políticos e econômicos.

Uma vez que é uma iniciativa global das Nações Unidas, toma-se como fonte o site oficial do movimento ${ }^{4}$ e a capa do site da ONU Mulheres de cada um dos países selecionados para este estudo. Os dados da investigação foram coletados considerando as informações/notícias encontradas sobre a campanha ao pesquisar pela expressão HeForShe ou ElesPorElas no campo de busca dos respectivos sites. Cabe salientar que, em razão do volume de dados encontrados, não é possível dar conta das informações relativas a todos os períodos desde o lançamento da campanha. Assim, do total de dados coletados, para fins de recorte e buscando promover o debate proposto por este estudo, foram selecionados os episódios em que a promoção da igualdade de gênero tem maior destaque.

No site mundial da HeForShe, é possível acompanhar de forma dinâmica a adesão de cada país à campanha, sendo que a organização classifica o nível de compromisso com a igualdade de gênero em Alto, Médio ou Baixo. De forma global, até 0 levantamento realizado dia 21 de abril de 2021, o site indicava que mais de 2,2milhões de pessoas se comprometeram com 0 movimento. Esse número revela o total de assinaturas virtuais, que permitem, de forma remota, a adesão de toda a população mundial, denotando uma simpatia ao tema de igualdade promovido pela campanha. Na oportunidade, o site também quantificou que a ONU Mulheres gerou mais de 1,3bilhões de conversas nas redes sociais, 1,7milhões de compromissos HeForShe e mais de 1,1mil eventos comunitários HeForShe (Figura 2). 
Figura 2: Status global de assinaturas em adesão à campanha

\section{COMPROMETA-SE COM A IGUALDADE DE GÊNERO}

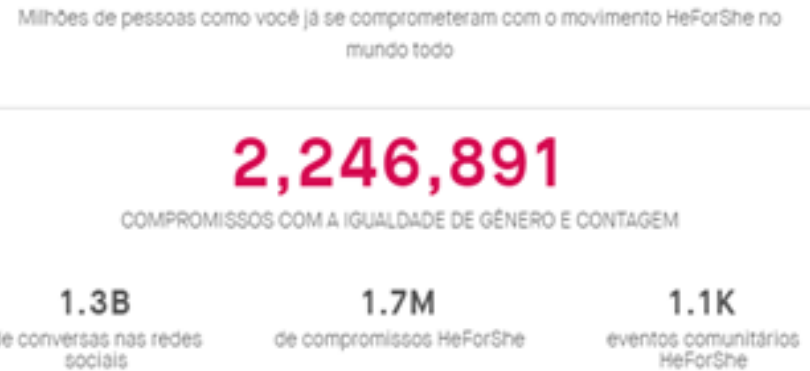

Fonte: HeForShe.

Os dados demonstram uma prática de mudança social estabelecida em nível mundial, com o envolvimento das pessoas tanto no âmbito das assinaturas como na participação em eventos e via redes sociais do movimento. 0 site da campanha, por sua vez, ao trazer o número de assinaturas em processo contínuo de atualização, apresenta uma prática discursiva (Fairclough, 2001), trazendo a força desse discurso como elemento de referência, além de gerar uma lógica de monitoramento da campanha, que ainda se apresenta ativa, mesmo que trazendo baixos índices de evolução.

Ao analisar os países selecionados, percebe-se uma adesão considerada alta pelo movimento, conforme o quadro 1. Porém, passados mais de seis meses de uma primeira coleta para o estudo, tanto o Brasil como o México não apresentam uma evolução significativa no processo de adesão a esse comprometimento quando comparamos dados coletados em setembro de 2020 e o novo recorte, em abril de 2021, conforme indicado no quadro 1. Nesse intervalo, o Brasil cresceu em 3,7\% e 0 México em 3,38\% o número de assinaturas.

Quadro 1: Adesão por país

\begin{tabular}{|c|c|c|c|}
\hline País & Adesão (no absolutos) em 10/09/2020 & Adesão (n⿳0 absolutos) em 21/04/2021 & Nível de Compromisso \\
\hline Brasil & 71.038 & 73.664 & Alto \\
\hline México & 137.782 & 142.443 & Alto \\
\hline
\end{tabular}

Fonte: elaborado pelas autoras, com base nos dados do site do movimento.

Na capa do site ONU Mulheres Brasil (Figura 3), a campanha aparece em destaque como uma aba - ElesPorElas - na barra das informações principais, no topo da página, direcionando para a página da campanha no país ${ }^{5}$.

5 Disponível em: http://www.onumulheres.org.br/elesporelas/. Acesso em: 21 abr. 2021. 
Figura 3: Capa do site ONU Mulheres Brasil

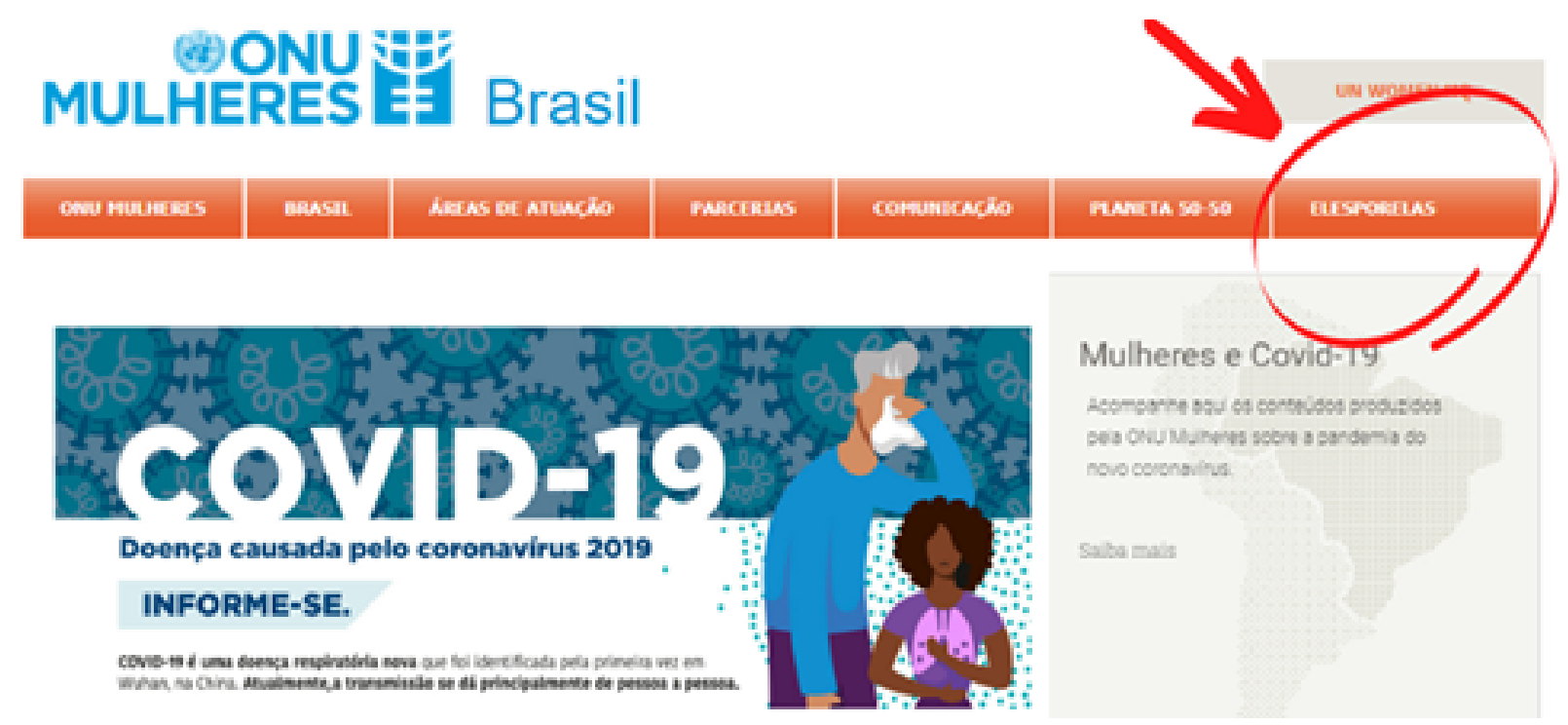

Fonte: ONU Mulheres.

No Brasil, a campanha \#HeForShe ou \#ElesPorElas tem seu lançamento potencializado no dia 24 de junho de 2015, quando há a apropriação midiática do canal de televisão por assinatura GNT, que projetou a campanha para uma determinada classe populacional com a meta de atingir 100mil assinaturas de adesão. Diversas ações foram realizadas pelo canal, tendo como ênfase a discussão e o engajamento de homens e mulheres à causa, utilizando, para isso, a visibilidade de artistas que se somaram à campanha para incentivar a adesão e o apoio do público.

Posteriormente, no dia 5 de fevereiro de 2018, a ONU lança a campanha \#CarnavalElesPorElas ${ }^{6}$, com enfoque no respeito à mulher, principalmente durante o período do Carnaval, considerado uma festa patrimônio cultural do Brasil, mas também um período fortemente marcado pela cultura do assédio sexual. A campanha objetiva modificar os dados registrados no ano anterior: nos quatro dias de feriado do Carnaval de 2017, a Central de Atendimento à Mulher (Disque 180) registrou mais de 2 mil atendimentos a mulheres vítimas de diversos tipos de agressão (Gasman, 2018). Sob a ótica da prática discursiva, há uma adaptação da hashtag, com inserções de contextos pontuais, como o Carnaval ou a covid-19.

Em 23 de abril de 2020, a campanha incorpora o contexto da pandemia e busca relatos de homens que promovem a igualdade de gênero dentro de casa, considerando que o tempo de permanência nos domicílios é maior no período. Tal prática discursiva apresenta o que Fairclough (2001) indica como força e coerência, considerando o alinhamento de contextos globais que afetaram diretamente a realidade doméstica de grande parte dos domicílios do Brasil. 0 principal enfoque do discurso é a redução das desigualdades de gênero e da sobrecarga das mulheres.

O compartilhamento de tarefas de trabalho doméstico e de cuidado com crianças, adolescentes, pessoas idosas e com deficiência é uma das ações mais concretas que homens podem assumir em suas casas e junto às suas famílias para responder à pandemia da covid-19 (ONU Mulheres, 2020).

A ação digital se dá pelo uso da hashtag \#ElesPorElasEmCasa (\#HeForSheAtHome) e faz um chamamento para o envio de histórias e compartilhamento via mídias sociais.

6 Disponível em: http://www.onumulheres.org.br/noticias/a-responsabilidade-sobre-o-assedio-e-do-assediador-por-nadine-gasman/. Acesso em: 21 abr. 2021. 
Ainda se percebe a possibilidade de regionalização do discurso da campanha, como no exemplo do Comitê Gaúcho Impulsor do Movimento \#ElesPorElas \#HeForShe que, em junho de 2020, no Rio Grande do Sul, lança a campanha Máscara Roxa. A campanha ainda está em curso e tem como propósito contribuir para a redução dos casos de violência decorrentes do isolamento pela pandemia. Consiste em ter farmácias como canais facilitadores de denúncia de violência contra mulheres. Ao chegar à farmácia, a mulher deve pedir a máscara roxa, que é a senha para que o atendente saiba que se trata de um pedido de ajuda. Na sequência, o profissional deve informá-la de que o produto está em falta, pegando alguns dados para avisá-la quando chegar.

Conforme depoimento do coordenador da campanha, Edegar Pretto, no contexto da pandemia e do isolamento, muitas vítimas não conseguem sequer fazer uma ligação para pedir ajuda. Então, o que a campanha propõe é "unir o poder público e a sociedade em um verdadeiro cerco aos agressores. Nós queremos que eles se sintam acuados, com medo, e não as mulheres" (No RS..., 2021). Por meio de Orientações Políticas, Culturais e Ideológicas (Fairclough, 2001), a prática social se configura neste tipo de campanha, produzindo sentidos aderentes ao discurso da campanha global da organização ONU Mulheres.

Ainda, em relação à pandemia da covid-19, cabe destacar outra leitura de contexto relevante junto aos dados encontrados no site ONU Mulheres Brasil. No primeiro semestre de 2020, as notícias e campanhas estavam mais voltadas à questão do aumento das agressões contra a mulher, ampliadas pelas condições de isolamento social, bem como da igualdade na distribuição de atividades e responsabilidades domésticas. Já no segundo semestre, notícias e programas voltados à recuperação socioeconômica começaram a dividir espaço com as demais informações, um reflexo mundial da pandemia e de seus diversos efeitos. Conforme pesquisa do IPEA em conjunto com a ONU Mulheres (ONU Mulheres, 2021), com a covid-19, mais de 2 milhões de trabalhadoras domésticas perderam seus empregos só em 2020, tornando-se a segunda categoria mais afetada durante a pandemia. A alta informalidade e o limitado acesso a direitos trabalhistas as deixam em situação de maior vulnerabilidade ante as crises, seja econômica, seja sanitária, ou composta, como é o caso da gerada pela pandemia.

Em âmbito geral, a campanha \#ElesPorElas brasileira apresenta uma linha do tempo e desdobramentos com ênfase no respeito à mulher, tendo como pilar os dados de violência doméstica e o combate ao abuso e ao assédio, crimes evidenciados em índices de denúncia e continuamente relatados pela mídia no país. Ainda, a imagem e os depoimentos das celebridades acionam a interdiscursividade (Fairclough, 2001) com temas interseccionais ao de gênero, especialmente o de raça. Salientase que tal foco pode ser paradoxal, pois a associação de artistas brasileiros à campanha, por um lado chancela a causa, promovendo sua visibilidade, mas por outro, empresta um olhar que pode parecer menos realista, mais associado à ficção, inerente ao fazer artístico.

Em termos de prática discursiva (Fairclough, 2001), a campanha \#HeForShe, no Brasil, tem seu versionamento ao português ampliado e consistente, com o uso da \#ElesPorElas. É curioso o fato de o Brasil usar no plural esse chamamento, diferentemente dos versionamentos em espanhol, como observado nos demais países da América Latina.

Na capa do site ONU Mujeres México ${ }^{7}$, a Campanha HeForShe (sem tradução para o espanhol) aparece em meio às informações distribuídas na página, destacada pela identidade visual da campanha, como é possível observar na Figura 4. 
Figura 4: Capa do site ONU Mujeres México

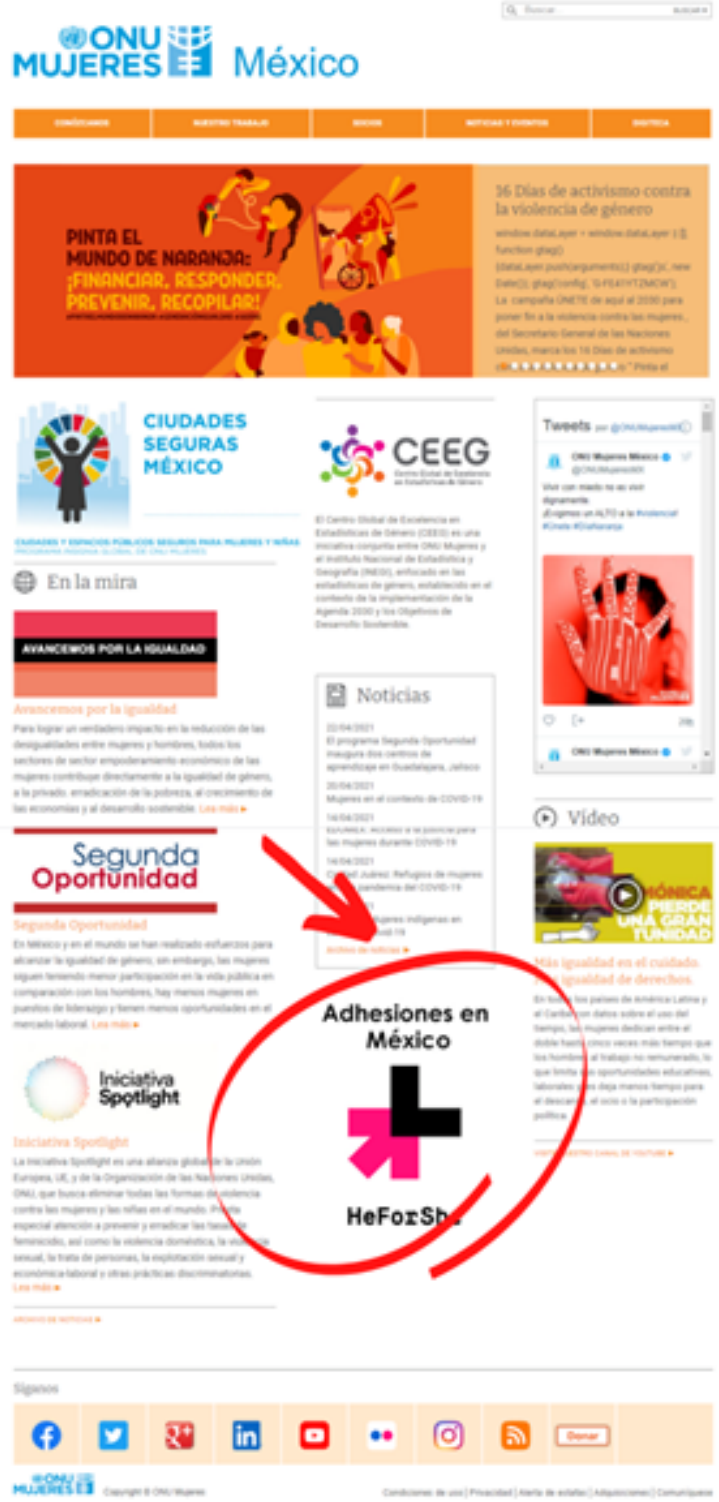

Fonte: https://mexico.unwomen.org/.

O México é um país que se destaca na apropriação do movimento \#HeForShe, principalmente com o enfoque da projeção da mulher na política do país, ampliando sua presença e representação na área pública. 0 lançamento da campanha \#HeForShe ou \#HeForSheMX ocorre em 5 de março de 2015, com uma coletiva de imprensa. A data tem como marco o dia internacional da mulher. A hashtag foi trend topic em nível nacional.

Sequencialmente, em 20 de outubro de 2017, nove partidos políticos se somaram à campanha HeForShe para priorizar a igualdade de gênero no processo eleitoral de 2017 a 2018. 0 resultado efetivo desta ação se dá quando, em 6 de junho de 2019, o país aprova a reforma constitucional sobre a paridade de gênero, tornando o México o primeiro país da América Latina e Caribe a garantir que metade dos cargos dos três níveis de governo e poderes da União e órgãos autônomos sejam ocupados por mulheres. Há, portanto, uma prática de mudança social efetiva, trazendo orientações políticas relevantes na ótica de Fairclough (2001). 0 México ocupa o quinto lugar no Ranking Mundial de Mulheres no Parlamento, com 48,2\% na Câmara dos Deputados e 49,2\% no Senado.

Já em 16 de abril de 2020, há o lançamento da hashtag \#HeForSheDesdeCasa, com a oferta de um guia8 para auxiliar a criar espaços colaborativos no cotidiano durante a quarentena trazida pela covid-19. A ênfase se dá nas masculinidades positivas e em como ambientes colaborativos e saudáveis com perspectiva da igualdade de gênero são criados diariamente. A iniciativa 
mexicana busca orientar os homens, de maneira clara, sobre quais medidas eles podem adotar para prevenir a violência contra as mulheres e meninas, como eles podem agir para reduzir as desigualdades de gênero, que se acentuam na demanda cotidiana doméstica e familiar em resposta à covid-19, e como eles podem gerir as próprias emoções diante da pandemia.

Ainda no contexto associado à pandemia da covid-19, o site ONU Mujeres México lança, em julho de 2020, uma ação chamada "Heroínas: Las Mujeres en el contexto de covid-19" (ONU Mujeres México, 2020). Esta ação não está vinculada à campanha \#HeForShe, mas sinaliza o contexto em que se enredam os sentidos produzidos pelo discurso da ONU Mujeres deste país. Conforme o site, o objetivo da ação é, através das histórias de mulheres heroínas em meio à pandemia, visibilizar a contribuição de mulheres à sociedade mexicana no contexto da covid-19. Um discurso que evidencia a busca pela posição de uma mulher com papel social e político ativos, alinhados com os resultados observados no engajamento da mesma ordem na campanha \#HeForShe.

\section{CONSIDERAÇÕES FINAIS}

Este estudo teve como objetivos analisar o discurso e a apropriação da campanha HeForShe promovida pela ONU Mulheres no Brasil e no México, além de discutir a potência dessas ações, relacionando os achados com os contextos locais e a contingência global, como a pandemia.

Para visualizar estes achados, sintetizamos as principais similaridades e diferenças na construção da campanha no Brasil e no México (Quadro 2).

Quadro 2: Síntese dos resultados

\begin{tabular}{|c|c|c|}
\hline & Brasil & México \\
\hline \multirow{2}{*}{$\begin{array}{l}\text { Diferenças - } \\
\text { Contexto Geral }\end{array}$} & $\begin{array}{l}\text { 1. Ênfase do discurso na imagem de } \\
\text { celebridades brasileiras, em maior parte } \\
\text { atores reconhecidos, que chancelam a } \\
\text { campanha e promovem sua visibilidade. }\end{array}$ & $\begin{array}{l}\text { 1. Ênfase do discurso com o foco da } \\
\text { projeção da mulher na esfera política do } \\
\text { país, ampliando sua participação e, em } \\
\text { consequência, sua representação. }\end{array}$ \\
\hline & $\begin{array}{l}\text { 2. Campanha com espaço na mídia nacional, } \\
\text { mas com menos evidências de práticas sociais. }\end{array}$ & $\begin{array}{l}\text { 2. Campanha com apelos mais racionais, } \\
\text { aponta para prática social com ênfase } \\
\text { na orientação política e ideológica. }\end{array}$ \\
\hline $\begin{array}{l}\text { Diferenças - } \\
\text { Contexto da } \\
\text { Pandemia }\end{array}$ & $\begin{array}{l}\text { 3. Destaque maior ao tema sensível e } \\
\text { predominante da violência contra a mulher. }\end{array}$ & $\begin{array}{l}\text { 3. Valorização das mulheres no espaço } \\
\text { público e social, colocando-as como } \\
\text { heroínas da linha de frente da pandemia. }\end{array}$ \\
\hline \multirow{4}{*}{$\begin{array}{l}\text { Similaridades - } \\
\text { Contexto Geral }\end{array}$} & \multicolumn{2}{|c|}{$\begin{array}{l}\text { 1. Corresponsabilidade. Destaque da campanha para a mensagem de que } \\
\text { homens e meninos têm papel fundamental na equidade de gêneros. }\end{array}$} \\
\hline & \multicolumn{2}{|l|}{ 2. Ênfase na busca de adesões ao movimento. } \\
\hline & \multicolumn{2}{|c|}{ 3. Autopromoção da ONU em seu papel e relevância para a mobilização mundial. } \\
\hline & \multicolumn{2}{|c|}{$\begin{array}{l}\text { 4. Desdobramento do discurso da campanha para a temática da violência } \\
\text { baseada em gênero, em uma visível relação cultural e histórica colonialista } \\
\text { de violência em relação à mulher na América Latina. }\end{array}$} \\
\hline $\begin{array}{l}\text { Similaridades } \\
\text { - Contexto da } \\
\text { Pandemia }\end{array}$ & \multicolumn{2}{|c|}{$\begin{array}{l}\text { 1. Discursos voltados para a atenção à desigualdade de responsabilidade pelo cuidado doméstico e } \\
\text { humano das mulheres, reforçada na pandemia. \#HeForSheDesdeCasa ou \#ElesPorElasEmCasa. }\end{array}$} \\
\hline
\end{tabular}


É possível notar que a campanha e seus desdobramentos discursivos mantiveram o destaque ao aspecto essencial da necessidade do entendimento por parte dos homens e meninos sobre seu papel fundamental na equidade de gêneros, buscando gerar um sentimento de corresponsabilidade. É evidente a ênfase na busca de adesões ao movimento, como garantia do reconhecimento da causa fundante do HeForShe como perspectiva de autopromoção da ONU bem como de chancelar relevância para a mobilização mundial.

Ainda, há um especial desdobramento do discurso da campanha para a temática da violência baseada em gênero, em uma visível relação cultural e histórica colonialista de violência em relação à mulher na América Latina. Os resultados nos indicam a adaptação da campanha em derivações do uso da hashtag no Brasil e no México, conforme determinados contextos. Sob a ótica da prática discursiva (Fairclough, 2001), há uma coerência nessa adequação de consumo do discurso da campanha que visa gerar uma mudança social efetiva com a produção de sentido regional compartilhado como o festival nacional aludido na \#CarnavalElesPorElas (Brasil) ou a ainda desigual responsabilidade pelo cuidado doméstico e humano (Lamas, 2007) das mulheres latinas, reforçada na pandemia (\#HeForSheDesdeCasa ou \#ElesPorElasEmCasa ou \#HeForSheAtHome).

O discurso presente na campanha \#HeForShe no México evidencia a prática social com ênfase na orientação política e ideológica e na promoção de sentidos, principalmente com o enfoque da projeção da mulher na esfera política do país, ampliando seu espaço e sua representação. Outros focos da campanha são valorizar as masculinidades positivas e as maneiras como ambientes colaborativos e saudáveis com perspectiva da igualdade de gênero são criados diariamente, principalmente considerando a pandemia. Mesmo com a problemática da covid-19, o discurso da ONU Mujeres ganha tons sociais de valorização e visibilidade da mulher no espaço público e social, colocando-as como heroínas da linha de frente da pandemia, um valor associado aos demais enfoques políticos e sociais encontrados na análise da campanha \#HeForShe no México.

Por outro lado, no Brasil, há uma maior ênfase na prática discursiva, voltada ao consumo do conteúdo das celebridades brasileiras que chancelam a campanha e promovem sua visibilidade, mas que emprestam um olhar que pode parecer mais associado à ficção e, portanto, com menos evidências de práticas sociais. Ainda na ótica da prática discursiva (Fairclough, 2001), a campanha \#HeForShe, no Brasil, tem seu versionamento amplo ao português e ao plural, com o uso da hashtag \#ElesPorElas. No contexto da pandemia, os discursos analisados ressaltam o tema sensível e predominante da violência contra a mulher, bem como das desigualdades domésticas e profissionais.

A ONU Mulheres, ao promover sua materialização discursiva por seus diversos espaços comunicacionais, se posiciona como uma organização que empresta às campanhas e a seus versionamentos multinacionais seu espaço de poder, de modo que os discursos, embora não aleatórios e/ou desprovidos de intenção, talvez ainda não consigam mobilizar vontades e realidades de forma ampliada, mas sim processual. 0 horizonte ético é evidente, mas as mudanças sociais ainda precisam de contínuo acionamento de texto e prática discursiva para que a igualdade de gênero possa se tornar realidade.

\section{REFERÊNCIAS}

COMISIÓN ECONÓMICA PARA AMÉRICA LATINA Y EL CARIBE. La autonomía de las Mujeres en escenarios económicos cambiantes. Santiago: Cepal, 2019.

CRENSHAW, Kimberlé. Documento para o encontro de especialistas em aspectos da discriminação racial relativos ao gênero. Revista Estudos Feministas, Florianópolis, v.10, n.1, p.171-188, 2002.

FAIRCLOUGH, N. Discurso e mudança social. Brasília, DF: Editora da UnB, 2001. 
GASMAN, Nadine. \#CarnavalElesPorElas - A responsabilidade sobre o assédio é do assediador. ONU Mulheres, Brasília, DF, 5 fev. 2018. Disponível em: http://www.onumulheres.org.br/noticias/a-responsabilidade-sobre-o-assedio-e-do-assediadorpor-nadine-gasman/. Acesso em: 21 abr. 2021.

KAUER, Carolina; ALVES, Denise A.; CARVALHO, Cristiane M. Similaridades e diferenças na promoção da igualdade de gênero: um estudo da campanha HeForShe na América Latina. In: CONGRESO DE LA ASOCIACIÓN LATINOAMERICANA DE INVESTIGADORES DE LA COMUNICACIÓN, 15., 2020, Medellín. Anais [...]. Medellín: UPB/ALAIC, 2020.

LAMAS, Marta. Género, desarrollo y feminismo en América Latina. Pensamiento iberoamericano, Madrid, n.0, p.133-152, 2007. MAFRA, Rennan Lanna Martins. Mobilização social e comunicação: por uma perspectiva relacional. Mediação, Belo Horizonte, v.11, n.10, p.106-118, 2010.

NO RS, mulheres vítimas de violência podem denunciar em farmácias. PT, [s.l.], 9 abr. 2021. Disponível em: https://pt.org.br/ no-rs-mulheres-vitimas-de-violencia-podem-denunciar-em-farmacias/. Acesso em: 16 ago. 2021.

ONU MUJERES MÉXICO. Heroínas: las Mujeres en el contexto de covid-19. ONU Mujeres México, Ciudad de México, 2 jul. 2020. Disponível em: https://mexico.unwomen.org/es/noticias-y-eventos/articulos/2020/06/heroinas-covid19/heroinas-covid. Acesso em: 25 abr. 2021.

ONU MULHERES. \#ElesPorElasEmCasa incentiva homens brasileiros a mostrar tarefas domésticas assumidas na quarentena da covid-19. ONU Mulheres, Brasília, DF, 6 mai. 2020. Disponível em: http://www.onumulheres.org.br/noticias/elesporelasemcasaincentiva-homens-brasileiros-a-mostrar-tarefas-domesticas-assumidas-na-quarentena-da-covid-19/. Acesso em: 26 abr. 2021.

ONU Mulheres Brasil. Série aborda direitos e vulnerabilidades de trabalhadoras domésticas na covid-19. ONU Mulheres, Brasília, DF, 21 jun. 2021. Disponível em: https://www.onumulheres.org.br/noticias/serie-aborda-direitos-e-vulnerabilidadesde-trabalhadoras-domesticas-na-covid-19/. Acesso em: 30 jun. 2021.

RIGGIROZZI, Pia; GRUGEL, Jean. La legalización del aborto en Argentina es sólo el comienzo de la batalla por los derechos reproductivos en América Latina. LSE, London, 18 fev. 2021. Disponível em: https://blogs.lse.ac.uk/latamcaribbean/2021/02/18/ la-legalizacion-del-aborto-en-argentina-es-solo-el-comienzo-de-la-batalla-por-los-derechos-reproductivos-en-americalatina/. Acesso em: 1 jul. 2021.

SAMPAIO, Rafael. Propaganda de A a Z. Rio de Janeiro: Elsevier, 2003.

SANTOS, Boaventura de S. Entre próspero e caliban: colonialismo, pós-colonialismo e inter-identidade. In: RAMALHO, Maria Irene; RIBEIRO, António Sousa (org.). Entre ser e estar. raízes, percursos e discursos da identidade. Porto, Portugal: Afrontamento, 2001.

TORO, José B.; WERNECK, Nísia M. D. Mobilização social: um modo de construir a democracia e a participação. Belo Horizonte: Autêntica, 2004.

Artigo submetido em 28.04.2021 e aprovado em 09.08.2021. 